\title{
The Challenge of Becoming International
}

Katia Regina H. C. Dias President of $\mathrm{SBPqO}$ ust as science has progressed with time, so has the Brazilian Division of the IADR, known by its domestic acronym, SBPqO. It has endeavored to adapt to the new realities of different historical moments. The year of 2007 witnessed a major step in the direction of progress and development.

Our 24 $4^{\text {th }}$ Annual Meeting, held in partnership with the $2^{\text {nd }}$ Meeting of the Latin American Federation (FLA) of the International Association of Dental Research (IADR), was a great success, with the participation of representatives of several Latin-American countries and also of the IADR. A total of 3,500 participants attended and 3,128 papers were presented.

During the meeting, Professor Sigmar de Mello Rode took office as the President of the FLA. We have the privilege of bearing witness to the beginning of a new era, an era of SBPqO's coming of age and becoming international.

We are now the major Latin American division of IADR, and we are acknowledged both for the quality and quantity of our research projects, an accomplishment that has enabled us to host the IADR Meeting of 2012, among others.

We are living a unique moment of progress and recognition of Brazilian Dentistry, also reflected by the candidacy of Professor Maria Fidela de Lima Navarro to the Vice-presidency of the IADR.

Our official journal, The Brazilian Oral Research (BOR) has burgeoned in like manner. In 2007, it modernized its layout so that it could meet the standards of the best international journals. On this course, we have counted on the support of Johnson \& Johnson.

It is noteworthy to mention that partnerships with the business sector are encouraged by the National Graduate Programs Development Plan of CAPES (Coordination for the Improvement of Higher Education Personnel) which emphasizes the importance of such actions as a means of funding research in our environment.

The goal for 2008 is to broaden our international reach even more. We count on your support, criticism and suggestions to further this endeavor. These are new times, with ever greater challenges that will undoubtedly help make the BOR and the SBPqO more distinguished in the dental research arena. 